\title{
YUCOMAT 2008 Features Topics from Designing Materials on the Atomic Scale by Nanotechnology to Advanced High-Tech Applications
}

On September 8-12, 2008, Herceg Novi, Montenegro, was once again the host of the Annual Conference of the Materials Research Society of Serbia (MRS-Serbia) and the Materials Research Society of Montenegro (yet to be officially established): YUCOMAT 2008, the general sponsor of which was the Institute of Technical Sciences of the Serbian Academy of Sciences and Arts.

At the Opening Ceremony, Dragan

\section{www.yu-mrs.org.yu}

Uskokovic, the president of MRS-Serbia and the director of the Institute of Technical Sciences of the Serbian Academy of Sciences and Arts, welcomed the attendees. He said, "[The] Materials Research Society of Serbia has this year become the 27th member of the Federation of European Materials Research Societies (FEMS), which gathers more than 20,000 researchers from the field of materials science.... The prime

\section{YUCOMAT 2008 Awards}

\section{Best PhD thesis}

Magdalena Stevanovic (Inst. of Technical Sciences of SASA, Belgrade, Serbia) for "Synthesis, Characterization, and Degradation of Poly(DL-Lactide-co-Glycolide) Nanospheres Containing Ascorbic Acid."

\section{Best MSc thesis}

Marija Jevtic (Inst. of Technical Sciences of SASA, Belgrade, Serbia) for "Sonochemical Synthesis and Characterization of Hydroxyapatite and Poly(DLLactide-co-Glycolide)-Hydroxyapatite Composite."

\section{Best oral presentation}

Sanja Ristic (Polytechnic Univ., Brooklyn, USA) for "Using Dielectric Relaxation Spectroscopy and Dynamic Mechanical Spectroscopy to Study Molecular Dynamics of Dendrimers in Hydrophobic/Hydrophilic Media."

\section{Best posters}

Joanne Kwon (Univ. of Cambridge, UK) for "Co-Polymer/ Bioceramic Composite for Coating Orthopaedic Implants."

Asja Veber (Inst. Jozef Stefan, Ljubljana, Slovenia) for "The Thickness, Morphology, and Structure of Sol-Gel $\mathrm{Bi}_{12} \mathrm{SiO}_{20}$ Thin Films."

Jelena Pavlicevic (Faculty of Technology, Novi Sad, Serbia) for "Thermal Stability of Model Irregular Poly(Urethane-Isocyanurate) Networks."

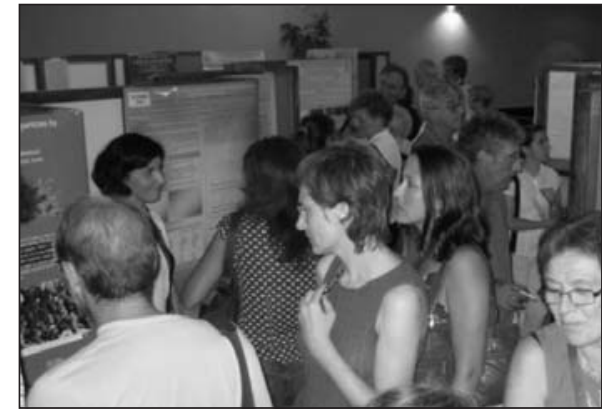

Participants of YUCOMAT 2008 engage in discussion during one of the poster sessions.

Katarina Marinkovic (Inst. of Technical Sciences of SASA, Belgrade, Serbia) for "Urea-Assisted Self-Combustion Aerosol Synthesis of $\mathrm{Y}_{3} \mathrm{~A}_{15} \mathrm{O}_{12}: \mathrm{Ce}^{3+}$."

task we received as the youngest member of FEMS is to get actively included in the creation of [the] entrepreneurial climate in Europe in our field, which would facilitate the formation of start-up companies led by university personnel."

Uskokovic also acknowledged that this was the first YUCOMAT conference in which the number of presentations by international speakers, from 35 countries from all continents, exceeded the number presented by national speakers. This is considered symbolic of the growth and scope of the YUCOMAT conferences. The conference consisted of three plenary sessions and five one-day symposia (including four oral and three poster sessions), dedicated to advanced methods in materials synthesis and processing, advanced materials for high-technology applications, nanostructured materials, composites, and biomaterials.

The conference also included a workshop entitled "Creating International Cooperation Teams of Excellence in the Emerging Biomaterial Surface Research," funded by the European Commission, as well as a round table discussion on "How to Write a Successful Proposal" and an exhibition of innovative scientific equipment. The official language of the meeting was English.

The detailed conference program can be accessed at www.yu-mrs.org.yu/ conference_program2008.htm. Selected manuscripts are scheduled to appear in Materials and Manufacturing Processes, published by Taylor and Francis; Surface Engineering, published by Maney; and Acta Physica Polonica, published by the Institute of Physics of Polish Academy of Sciences.

The next YUCOMAT Conference will also be held in Herceg Novi, on August 31-September 4, 2009. More information can be accessed at Web site www.yumrs.org.yu.

DRAGAN USKOKOVIC President of MRS-Serbia and Director of the Institute of Technical Sciences of the Serbian Academy of Sciences and Arts

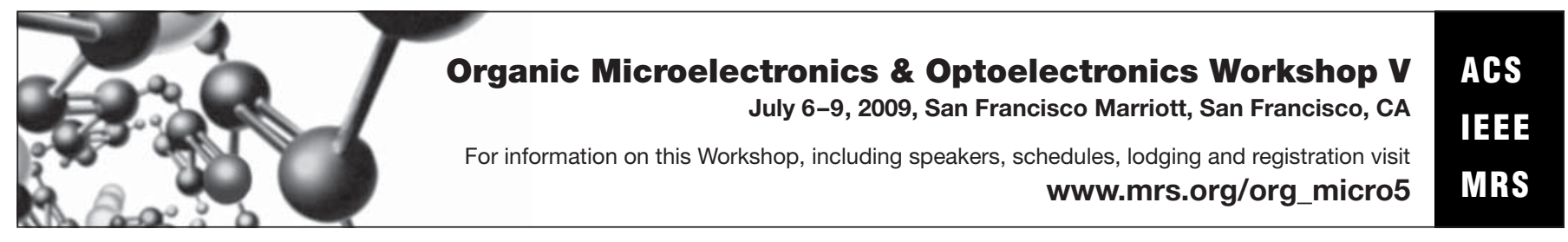

